\title{
Bio Technological Intervention with Platelet Rich Plasma for Assisted Regeneration of Sole
}

Sandeep Shrivastava*, Sparsh Naik, Bhushan Patil, Pankaj Kharabe, Anurag Gupta and Swapnil Joshi

Centre for Autologous Platelet Biotechnological Intervention (CAP_BI) J.N. Medical College, Datta Meghe Institute of Medical Sciences (DU), Wardha, Maharashtra, India

\begin{abstract}
With the advent of Regenerative medicine products in medicine, newer solutions are getting evolved for complex conditions. The Cellular therapies offer a new ray of hope by inducing regeneration of tissue at the site of damage. The cellular therapy led by platelet rich plasma (PRP) is one such key regenerative product. But there is a huge variability in its usage, particularly for wounds. The standardisation for clinical usage is not yet evolved, hence limiting the clinical application of the same.
\end{abstract}

The authors have developed a standard protocol "STARS" therapy, which utilises PRP as biotechnological tool, re-engineering the damaged tissue and gradually assisting the regeneration.

In this study we report 8 cases of wounds/ulcers over the sole being treated by it. The results are excellent and offer a milestone solution to non-healing wounds/ulcers over soles. These wounds are otherwise, very difficult to treat particularly as they are associated with high risks factors such as infection, Diabetes and old age. They are under constant pressure due to weight bearing and give way easily and do not heal.

The bioenginreeing of the sole tissues through PRP led STARS intervention is safe, effective and easily reproducible.

Keywords: Regenerative medicine products; Platelet rich plasma(PRP); Sandeep's technique for assisted regeneration of Skin (STARS); Non-healing ulcer of sole; Infection control and regeneration in wound

\section{Introduction}

The management of complex wounds is a huge challenge for modern medicine [1]. It consumes lots of resources require high expertise care and long medications, through local care of wounds; initially by cleaning and debridement of wounds, subsequently by regular dressings, now a day it is assisted by application of vacuum devices, which shrink and drain wounds. Along with these, the management essentially includes drugs such as antibiotics to prevent/control or treat infections [2-4]. Despite these they may not heal due to associated infections, old age, underlying diseases such as diabetes. Many of them are associated with permanent losses of skin, which could be primary due to severe trauma or secondary due to necrosis or infections.

A loss of skin over sole is a very peculiar problem. The sole is much specialised skin tailor made for weight bearing. Its surgical reconstruction to normal or near normal anatomy is not possible. Even expensive and highly specialised surgical procedures like split thickness, skin grafting or full thickness rotational or free flaps tend to fail.

A good solution would be assist \& bio-engineer the natural sole skin towards regeneration as a final coverage of wound. If this can be achieved independent of drugs and surgical intervention, it can be labelled as ideal solution.

The newer understanding of mechanisms of cellular therapy leading to angiogenesis, inflammation, cell proliferation, differentiation and metabolism is promoting researchers to develop solutions based on Regenerative medicine products 4 . The development of tissue engineering, explores the regenerative potentials innate to damaged/ deteriorating human tissues/organs, restoring the normal bodily function.

These advances in our understanding of regenerative cellular therapies and further development towards their successful clinical implementations through new tissue formation exponentially opens opportunities for survival and regeneration $[5,6]$. The key regenerative medicine products into the clinical usage being evolved includes Stem cells, mesenchymal stem cells and platelet rich plasma (PRP) [7,8] .The PRP was initially promoted by M. Ferrari in 1987 [9] as an autologous transfusion component after an open heart operation to avoid homologous blood product transfusion, there are now over 5200 entries in the NCBI for PRP across different disorders including wound healing, cosmetic, bone healing, osteoarthritis, hair transplantation and musculoskeletal tendonitis $[10,11]$. The platelets are rich in proteins, contain growth factors and cytokines. They release many bioactive proteins responsible for attracting macrophages, mesenchymal stem cells and osteoblasts that promote removal of degenerated and necrotic tissue, and enhance tissue regeneration and healing [12]. They release epidermal growth factor which promotes endothelial cell proliferations [13]. Recently biologics such as Platelet Rich Plasma gels are also used in the form of local dressing for such wounds [14-18]. This is based on biotechnologically modulating the environment towards the regeneration by PRP led cellular therapy in the wounds $[18,19]$.

A very interesting solution has been developed by the authors known as STARS therapy [20], which is based solely on treating wounds with PRP

*Corresponding author: Sandeep Shrivastava, Centre for Autologous Platelet Biotechnological Intervention (CAP_BI) J.N. Medical College, Datta Meghe Institute of Medical Sciences (DU), Wardha, Maharashtra, India, Tel: 917152287757 ; E-mail: drsandeepshrivastava@hotmail.com

Received September 03, 2017; Accepted September 29, 2017; Published October 07, 2017

Citation: Shrivastava S, Naik S, Patil B, Kharabe P, Gupta A, et al. (2017) Bio Technological Intervention with Platelet Rich Plasma for Assisted Regeneration of Sole. J Tissue Sci Eng 8: 206. doi: 10.4172/2157-7552.1000206

Copyright: ( 2017 Shrivastava S, et al. This is an open-access article distributed under the terms of the Creative Commons Attribution License, which permits unrestricted use, distribution, and reproduction in any medium, provided the original author and source are credited. 
infiltration and a step ahead previous PRP usages as above. Out of 250 wounds treated by STARS therapy, authors aim in this study is to analyse the outcome of STARS therapy toward "Sole-regeneration" while treating wounds ulcers of Sole. This study includes 8 such cases outcome analyses.

\section{PRP Biotechnology}

The current trends of Biological interventions include mainly tissue engineering, cell-based therapies, and platelet rich plasma (PRP) therapies. Tissue engineering is mostly with cells loaded within 3D printed scaffolds. The $3 \mathrm{D}$ printing is still a evolving concept in medical intervention and have a very limited clinical utilisation as of now. The cell therapies, including mesenchymal stem cells (MSCs), embryonic stem cells or induced pluripotent stem cells (iPSC) which are mostly cultured in vitro. However, these therapies are advancing at a slower pace because reprogramming raises serious concerns about safety due to their genetic instability and potential to trigger uninhibited growth which may lead to cancers or cancer like conditions [21]. Hence the regulatory requirements for cell therapy involve multiple preclinical experiments to demonstrate their safety and non-teratogen effects in addition to strict statutory compliance in the preparation [22].

PRP, an autologous plasma fraction of peripheral blood, is the regenerative medicine intervention that is rapidly undergoing clinical implementations and usages. The PRP therapies involve minimal manipulation, and in general, regulatory requirements are easy to comply. PRPs can be easily prepared by in house procedures, providing that basic rules of quality are implemented [23].

\section{Properties of Platelet-rich Plasma towards Wound Healing and Regeneration:}

Platelet releasates have been used to treat wounds since 1980's $[24,25]$. PRP serves as a growth factor agonist and has both mitogenic and chemotactic properties. PRP functions as a tissue sealant and drug delivery system, with the platelets initiating wound repair by releasing locally acting growth factors [26] via $\alpha$-granules degranulation [27]. The secretory proteins contained in the $\alpha$-granules of platelets include platelet-derived growth factor (PDGF-AA, BB, and $\mathrm{AB}$ isomers), transforming growth factor- $\beta$ (TGF- $\beta$ ), platelet factor 4 (PF4), interleukin-1 (IL-1), platelet-derived angiogenesis factor (PDAF), vascular endothelial growth factor (VEGF), epidermal growth factor (EGF), platelet-derived endothelial growth factor (PDEGF), epithelial cell growth factor (ECGF), insulin like growth factor (IGF), osteocalcin $(\mathrm{Oc})$, osteonectin $(\mathrm{On})$, fibrinogen $(\mathrm{Ff})$, vitronectin $(\mathrm{Vn})$, fibronectin (Fn) and thrombospondin-1 (TSP-1) [28]. These growth factors aid healing by attracting un-differentiated cells in the newly formed matrix and triggering cell division. PRP may suppress cytokine release and limit inflammation, interacting with macrophages to improve tissue healing and regeneration, promote new capillary growth, and accelerate epithelialization in chronic wounds $[29,30]$.
Platelets in PRP also play a role in host defence mechanism at the wound site by producing signalling proteins that attract macrophages [31]; PRP also may contain a small number of leukocytes [32] that synthesize interleukins as part of a non-specific immune response. Previous studies of PRP have demonstrated antimicrobial activity against Escherichia coli, Staphylococcus aureus [31,32], including methicillin-resistant Staphylococcus aureus [31], Candida albicans [31] and Cryptococcus neoformans [33]. This suggests its role as antimicrobial and has the potential to eradicate the infective pathogens from the site and boost the healing process. This justifies its use as pharmacological therapy in wound healing.

\section{Sole Regeneration by PRP}

We hereby report a case series of 8 cases of complex sole wounds/ ulcers associated with infections and permanent skin losses treated with STARS therapy at our "Centre for Autologous Platelet therapy biotechnological Interventions (CAP_BI)" situated in tertiary care teaching hospital between 1st Jan, 2015 to 31st May 2017.

Each Patient was enrolled in the study after obtains the informed consents to undergo the treatment and meeting the inclusion criteria for STARS therapy. The "Sandeep's Technique's for assisted regeneration of skin" (STARS) therapy/protocol is developed at our institute by the author 1 [20], for treating complex wounds with Autologous Platelet Rich Plasma (PRP) as biotechnological intervention. The PRP is freshly prepared from autologous low volume venous blood of patient. Subsequently it is infiltrated uniformly in the subcutaneous tissue of the progressive wound margin. The infiltration is repeated on every 4 th day, till complete /near complete healing takes place and skin regenerates covering the wound. As per the protocol no drugs (antibiotics), surgeries or intense local care (except most saline daily occlusive dressing) was done.

The progress of wounds healing was photographed and recorded at every session. Outcomes are assessed clinically in terms of Complete healing of Ulcer, control of infection, Quality of skin regenerate (histopathological and Physical) and any adverse outcomes including complications. This is for the first time a protocol based solely on PRP, as mainstay treatment is used for complete healing of wound.

\section{Observations and Results}

The observations and results are as per Tables 1 and 2. The average age was 41 years. There were 5 females and 3 are males. 3 cases had diabetes type II and 1 had Juvenile diabetes (type I).

7 ulcers/wounds were infected at the start of therapy. The pus swabs taken from the wounds for bacterial culture and sensitivity, revealed initial growth of Staphylococcus aureus as key micro-organisms in most of them. The repeated weekly latest such culture report of all 7 cases was negative for any growth of any bacteria.

\begin{tabular}{|c|c|c|c|c|c|}
\hline Case No. & Age & Sex & Diagnosis & Co-morbidity \\
\hline 1 & 65 & F & Non healing ulcer & DM type II ,Hypertension \\
\hline 2 & 22 & F & Non healing ulcer & DM-Type I \\
\hline 3 & 8 & M & Post traumatic-crush injury & - \\
\hline 4 & 56 & M & Chronic Osteomyelitis of calcaen umm & DM type II \\
\hline 5 & 32 & M & Post traumatic- Crush injury & Staphylococci \\
\hline 6 & 54 & F & Non healing Ulcer & DM type II \\
\hline 7 & 24 & F & Chronic Osteomyelitis of calcaen umm & - & Staphylococci auerus \\
\hline 8 & 67 & F & Non healing Ulcer & - & Kleibsella, Staphylococi aureus \\
\hline
\end{tabular}

Table 1: Case wise details before treatment. 
Citation: Shrivastava S, Naik S, Patil B, Kharabe P, Gupta A, et al. (2017) Bio Technological Intervention with Platelet Rich Plasma for Assisted Regeneration of Sole. J Tissue Sci Eng 8: 206. doi: 10.4172/2157-7552.1000206

Page 3 of 5

\begin{tabular}{|c|c|c|c|c|}
\hline Case No. & $\begin{array}{c}\text { Initial Wound Size } \\
\text { (Sq. } \mathbf{~ c m})\end{array}$ & $\begin{array}{c}\text { Healing of wound at last } \\
\text { STARS session }\end{array}$ & Control of Infection & Quality of skin \\
\hline 1 & 24.4 & Near complete* & no growth & near normal** \\
\hline 2 & 26.4 & Near complete & no growth & near normal \\
\hline 3 & 16.1 & Near complete & no growth & near normal on both aspects of foot \\
\hline 4 & 64.4 & Near complete & no growth & near normal \\
\hline 5 & 96 & Near complete & no growth & near normal on both aspects of foot \\
\hline 6 & 30.4 & Near complete & no growth & near normal \\
\hline 7 & 11.4 & Near complete & no growth & near normal \\
\hline 8 & 21.84 & Near complete & no growth & near normal \\
\hline * Near Complete: with 1 sq. cm & & & - \\
** Near Normal: in terms of Colour, Elasticity, Thickness and Sensitivity & \\
\hline
\end{tabular}

Table 2: Case wise details at the end of treatment.

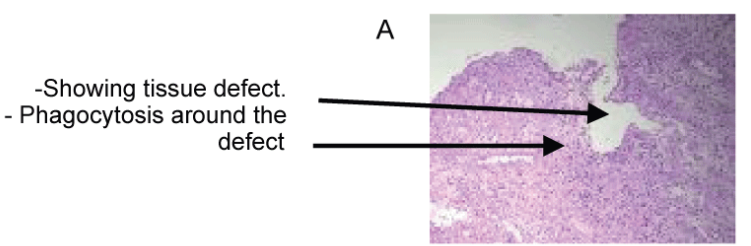

Defect Filling with NeoAngiotic tissue

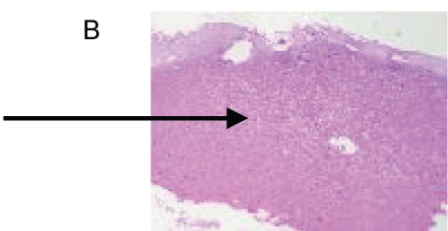

Defect Filling with band of collagen tissue

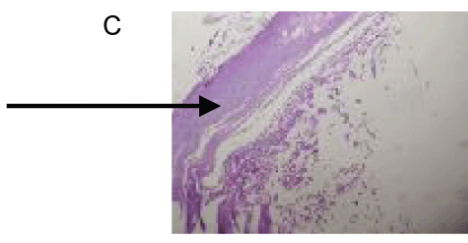

Defect is totally filled with near normal tissues.

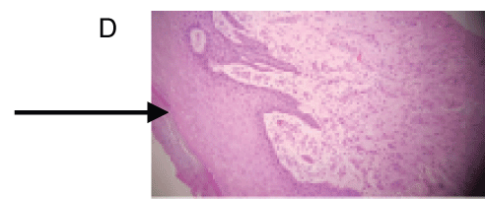

Figure 1: Serial histopathological examination during healing of wounds. A After $48 \mathrm{~h}$ of PRP Infiltration, B: On $10^{\text {th }}$ day: Defect filling with neo-angiotic tissue, C: On $21^{\text {st }}$ days: Defect filling with band of collagen tissue, D: On $42^{\text {nd }}$ day: Defect is totally filled with near normal tissues.

5 cases initially had a haemoglobin of less than $10 \mathrm{gm} \%$ (mean $8.9 \mathrm{~g} \%$ ) and needed further treatment to bring it to the basic level of $10 \mathrm{~g} \%$ before they became eligible to undergo STARS therapy. During treatment 2 of them required blood transfusion as their haemoglobin again fall below $10 \mathrm{~g} \%$. The latest mean haemoglobin at the end of treatment was $11.2 \mathrm{~g} \%$.

The average wound size was $36.36 \mathrm{sq}$. $\mathrm{cm}$. All the wounds eventually healed with near normal sole skin. Interestingly 2 wounds of crush injury had both dorsal and sole skin losses and both showed complete healing with regeneration of different skin types on each surface (Figures 1 and 2). This is not possible with any surgical interventions, as in vogue currently.

No major complications or adverse events were noted.
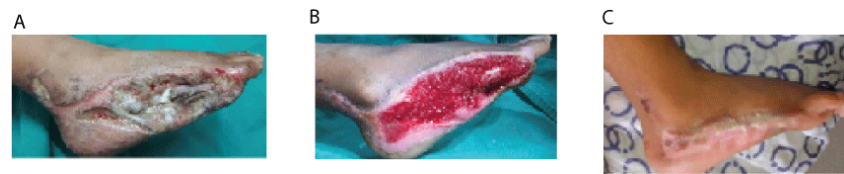

Figure 2: Case no. 5: A: After trauma B. At the beginning of therapy $C$ : At the end of 4 week $D$ : At the end treatment ( 8 weeks).
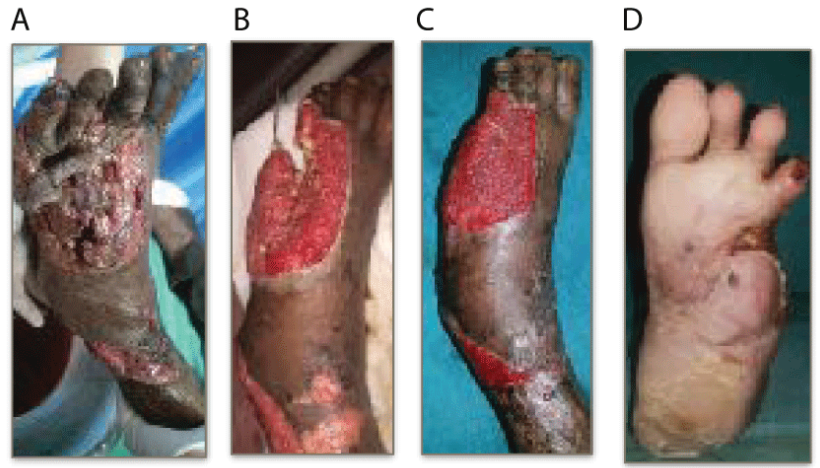

Figure 3: Case no. 2: A: After Trauma B,C: During treatment after 2 weeks D: At the end treatment ( 6 weeks)

\section{Discussion}

Mankind has been trying to deal with wounds from time immemorial. From the Galen's era of laudable pus (circa AD 180) to the present era, a lot has changed the way these troubling afflictions are dealt with. In these cases of non-healing wounds of the sole, the condition have caused prolong suffering and economic loss to the patient. Even if such wound were to heal, it would leave behind a non-functional scar. A very sophisticated and expensive surgical procedure like skin flap will be required to expedite healing, and still the results may not be satisfactory. Platelet derived growth factors have been known since 1974 to help in tissue regeneration. These growth factors can be made use of in wound regeneration. Platelet Rich Plasma is an excellent source of these factors. PRP gel is commercially available for use. There are many cases reported in different studies showing encouraging trends for PRP to be used as local application in the form of gel for promoting the healing of chronic wounds. But all these studies have used PRP as local application, adjunct to standard ulcer management $[29,30]$. However, these gels are expensive.

STARS therapy [20] is a bio-safe effective, efficient, and easily reproducible. It utilises the regenerative medicine biotechnological 
intervention product -autologous PRP, made from $20 \mathrm{ml}$ of freshly drawn autologous venous blood. We studied the utilisation of PRP as mainstay biotechnological intervention inducing and promoting its role as a regenerate product. Its effect on sole regeneration is very encouraging and it have healed the chronic ulcers/wounds over one of the most difficult sites assisting the natural regenerations to near normal skin of sole. The histopathological examination as depicted by the Figures $1 \mathrm{~A}-1 \mathrm{D}$ showed the healing progresses initially led by Phagocytes, followed by Neo-angiogenesis, than the collagen tissue filling the wound defect and finally at the end of 6 weeks, almost near normal skin tissue is formed.

The periodic infiltration with PRP induces different growth factor led changes in micro environment leading to lot of phagocytic activity in the beginning, followed by Neo-angiogenesis and then epithelization. This pattern of healing by PRP infiltration is observed as wound undergoes four gross but overlapping stages, during healing process. Initially there is control of infection and suppression of unhealthy tissue, further there is formation of granulation tissue, followed by epithelisation from margins progressing towards centre of wound and eventually maturation into near normal skin. These stages mimic the natural healing process. The stage of healthy granulation and filling up of defects is generally much faster than epithelization and maturation stage. The rate of healing is approximately $0.75 \mathrm{~mm}$ to $1 \mathrm{~mm} /$ day, varying with local conditions.

The quality of skin coverage is almost normal as per the thickness, texture and sensations .Hence have minimal risks for wound dehiscence's and recurrence even with full weight bearing, eliminating the need of any special foot wears by the patients. Though perhaps a more long term and larger studies will be needed to reinforce this.

The repeated culture showed progressive control of infection and no deterioration was noticed in any wound conditions. This is very significant as it indicates a very strong antimicrobial properties of PRP $[31,32]$. It has the potential to eliminate role of antibiotics in wound care, thus having a huge positive impact on antimicrobial resistance issues. Another interesting facts observed during the study is that no analgesics were seeked by patients. The mean VAS score varied from 0-3 for most of the time. This is again significant as NSAIDS in patients having co-morbidities as diabetics are detrimental and contraindicated.

The Local care included is very simple, just cleaning with soap based solution and occlusive dressings with moist saline. Huge resources are needed, otherwise for local care including usage of newer devices such as negative pressure devices. The PRP infiltrate eliminates any such need of intensive local cares and dressing, thus saving huge resources in terms of money and manpower.

No surgical interventions were needed. Thus eliminating any further morbidity of donor site to the patient. Also many a times the risks due to active infections and uncontrolled blood sugars are too high to undertake any surgical reconstructions. It does not need experts such as plastic/reconstructive surgeons, etc., to impart the STARS therapy. At our centre the therapy was imparted by trainee residents, who are basically medical graduates. With very little trainings they could undertake effective PRP preparation and conduct STARS session.

There were no adverse events or any complications noted in any patients, including the case of juvenile diabetes with uncontrolled very high level of sugar (ranging from $300-500 \mathrm{mg} / \mathrm{dl}$ ) throughout the treatment.

Though we took all precautions to exclude any possibility of haematological disorders in all the Patients and ensured that each of them had at least a haemoglobin level of $10 \mathrm{~g} \%$ or above and a normal platelet cunt of above $150,000 / \mathrm{ml}$. As the PRP used is autologous and freshly prepared, there is absolute no additional risks of any disease transmissions too. It can be safely given under all health care settings.

\section{Summary and Conclusion}

The biotechnological intervention with PRP through STARS therapy is exclusive of drugs, intense dressings and surgical interventions. The control of infections and pain is adequate. It leads to a predictable pattern of wound healing with minimised risk and damages. The quality of regenerated skin is near natural, which is impossible to be reconstructed by any other means, as of now. It is a treatment option which can be imparted with ease, and effectively by even ordinarily trained doctors in all health care settings, with minimum of equipment or infrastructure support. The PRP led STARS therapy is an effective and efficient way for tissue reengineering and assisted regeneration of sole.

\section{Limitation}

The conclusions are based on study involving 8 cases. Statistically it is too little for mean values.

\section{Recommendation}

The biotechnological intervention with a regenerative medicine product will be the "Game changer" and future of Medicine. It's an exciting translational clinical research towards finding an ideal solution for wound management.

Based on the results obtained, PRP interventions in complex wound management of sole can be undertaken, particularly for low resource health care development. Though it's too early and small evidence to effectively state, if this could be a complete solution, with no potential failures. But trends seem to be towards path breaking journey.

\section{Acknowledgement}

This project has a financial Intramural grant \& support by Datta Meghe Institute of Medical Sciences (DU), Wardha, MS, India.

\section{References}

1. Fife CE, Carter MJ (2012) Wound care outcomes and associated cost among patients treated in us outpatient wound centers: data from the US wound registry. Wounds 24: 10-17.

2. Gupta S, Jensen BB, Gabriel A, Holloway, Niezgoda J, et al. (2007) Differentiating negative pressure wound therapy devices: An illustrative case series. Wounds 19: 1-9.

3. Waniczek DA, Rudzki MK, Buda KK, Arendt J (2011) Searching for new wound healing strategies--problems and pitfalls. Wiad Lek 64: 313-319.

4. Skórkowska-Telichowska K, Czemplik M, Kulma A, Szopa J (2013) The loca treatment and available dressings designed for chronic wounds. J Am Acad Dermatol 68: e117-126.

5. Kuhbier JW, Reimers K, Radtke C, Vogt PM (2015) Regenerative therapy approaches in plastic surgery. Chirurg 86: $214-222$.

6. Haseltine WA (2011) Interview: commercial translation of cell-based therapies and regenerative medicine: Learning by experience. Interview by Emily CulmeSeymour. Regen Med 6: 431-435.

7. Martínez CE, Smith PC, Palma Alvarado VA (2015) The influence of plateletderived products on angiogenesis and tissue repair: A concise update. Front Physiol 20: 290.

8. Roubelakis MG1, Trohatou O, Roubelakis A, Mili E, Kalaitzopoulos I, et al (2014) Platelet-rich plasma (PRP) promotes fetal mesenchymal stem/stroma cell migration and wound healing process. Stem Cell Rev 10: 417-428. 
Citation: Shrivastava S, Naik S, Patil B, Kharabe P, Gupta A, et al. (2017) Bio Technological Intervention with Platelet Rich Plasma for Assisted Regeneration of Sole. J Tissue Sci Eng 8: 206. doi: 10.4172/2157-7552.1000206

9. Ferrari M, Zia S, Valbonesi M, Henriquet F, Venere G, et al. (1987) A new technique for hemodilution, preparation of autologous platelet-rich plasma and intraoperative blood salvage in cardiac surgery. Int J Artif Organs. 10: 47-50.

10. Mishra A, Pavelko T (2006) Treatment of chronic elbow tendinosis with buffered platelet-rich plasma. Am J Sports Med 34: 1774-1778.

11. Sharma S, Samal N, Khan SM (2015) Clinical effects of autologous platelet rich plasma in tennis elbow. Orthopedics and Rheumatology Open Access 11-5.

12. Boswell SG, Cole BJ, Sundman EA, Karas V, Fortier LA (2012) Platelet-rich plasma: A milieu of bioactive factors. Arthroscopy 28: 429-439.

13. Bertran Duchesne MP, Grenier D, Gagnon G (2010) Epidermal growth facto released from platelet-rich plasma promotes endothelial cell proliferation in vitro. J Periodont Res 45: 87-93.

14. Gao F, Wang JX, Han Y (2009) Research advance on application of plateletrich plasma in wound repair -- Review. Zhongguo Shi Yan Xue Ye Xue Za Zh 17: 840-843.

15. Rozman P, Bolta Z (2007) Use of platelet growth factors in treating wounds and soft-tissue injuries. Acta Dermatovenerol Alp Pannonica Adriat 16: 156-165.

16. Kazakos K, Lyras DN, Verettas D, Tilkeridis K, Tryfonidis M (2009) The use of autologous PRP gel as an aid in the management of acute trauma wounds. Injury 40: 801-805

17. Frykberg RG, Driver VR, Carman D, Lucero B, Borris-Hale C, et al. (2010) Chronic wounds treated with a physiologically relevant concentration of plateletrich plasma gel: A prospective case series. Ostomy Wound Manage. 56: 36-44.

18. Lacci KM, Dardik A (2010) Platelet-rich plasma: support for its use in wound healing. Yale J Biol Med 83: 1-9.

19. Pietrzak WS, Eppley BL (2005) Platelet rich plasma: Biology and new technology. J Craniofac Surg 16: 1043-1054.

20. Shrivastava S, Singh PK, Taywade S (2016) STARS therapy: Sandeep's technique for assisted regeneration of skin. Journal of Orthopedics and Allied Sciences 4: 57

21. Oerlemans AJ, van Hoek ME, van Leeuwen E, Dekkers WJ (2014) Hype and expectations in tissue engineering. Regen Med 9: 113-122.
22. Närhi MO, Nordström K (2014) Regulation of cell-based therapeutic products intended for human applications in the EU. Regen Med 9: 327-351.

23. GonshorA (2002) Technique for producing platelet rich plasma and platele concentrate: background and process. Int J Periodontics Restorative Dent 22 547-557.

24. Assoian RK, Komoriya A, Meyers CA, Miller DM, Sporn MB (1983) Transforming growth factor-beta in human platelets. Identification of a major storage site, purification and characterization. J Biol Chem 258: 7155-7160.

25. Assoian RK, Grotendorst GR, Miller DM, Sporn MB (1984) Cellula transformation by coordinated action of three peptide growth factors from human platelets. Nature 309: 804-806.

26. Sánchez-González DJ, Méndez-Bolaina E, Trejo-Bahena NI (2012) Plateletrich plasma peptides: Key for regeneration. Int J Pept 2012: 532519.

27. Marx RE (2004) Platelet-rich plasma: evidence to support its use. J Oral Maxillofac Surg 62: 489-496.

28. Banks RE, Forbes MA, Kinsey SE, Stanley A, Ingham E, et al. (1998) Release of the angiogenic cytokine vascular endothelial growth factor (VEGF) from platelets: significance for VEGF measurements and cancer biology. $\mathrm{Br} J$ Cancer 77: 956-964.

29. McAleer JP, Sharma S, Kaplan EM, Persich G (2006) Use of autologous platelet concentrate in a nonhealing lower extremity wound. Adv Skin Wound Care 19: 354-363.

30. Pietramaggiori G, Kaipainen A, Czeczuga JM, Wagner CT, Orgill DP (2006) Freeze-dried platelet-rich plasma shows beneficial healing properties in chronic wounds. Wound Repair Regen 14: 573-580.

31. Bielecki TM, Gazdzik TS, Arendt J, Szczepanski T, Król W, et al. (2007) Antibacterial effect of autologous platelet gel enriched with growth factors and other active substances: An in vitro study. J Bone Joint Surg Br 89: 417-420.

32. Tang YQ, Yeaman MR, Selsted ME (2002) Antimicrobial peptides from human platelets. Infect Immun 70: 6524-6533.

33. Steed DL, Goslen JB, Holloway GA, Malone JM, Bunt TJ, et al. (1992) Webster MW. Randomized prospective double-blind trial in healing chronic diabetic foot ulcers. CT-102 activated platelet supernatant, topical versus placebo. Diabetes Care 15: 1598-1560. 